\title{
PENGARUH PUBLIC SERVICE MOTIVATION TERHADAP KEPUASAN KERJA PERAWAT RSUD HAJI MAKASSAR
}

\author{
THE EFFECT OF PUBLIC SERVICE MOTIVATION ON NURSE'S JOB \\ SATISFACTION IN REGIONAL GENERAL HOSPITAL HAJI MAKASSAR
}

\author{
Armelia Permatasari ${ }^{1}$, Syahrir A. Pasinringi ${ }^{2}$, Abdul Rahman Kadir ${ }^{3}$ \\ ${ }^{1}$ Bagian Manajemen Rumah Sakit, Fakultas Kesehatan Masyarakat, Universitas Hasanuddin \\ ${ }^{2}$ Bagian Manajemen Rumah Sakit, Fakultas Kesehatan Masyarakat, Universitas \\ Hasanuddin ${ }^{3}$ Bagian Ekonomi, fakultas Ekonomi, Universitas Hasanuddin
} *Alamat Korespondensi: Armelia Permatasari, Fakultas Kesehatan Masyarakat, Universitas Hasanuddin, Makassar, 90154, Hp:
081280280089,_Email: lia_persari@yahoo.com

\begin{abstract}
Abstrak
Terdapat motivasi intrinsik yang memengaruhi kepuasan kerja pegawai di sektor publik yakni Public Service Motivation (PSM)dimana para pegawai yang lebih mementingkan memberikan pelayanan publik dibandingkan kepentingan pribadi. Penelitian ini bertujuan untuk menganalisis menganalisis pengaruh dimensi Public Service Motivation (PSM)terhadap kepuasan kerja perawat di RSUD Haji Makassar.Penelitian dilaksanakan di RSUD Haji Makassar, Jenis penelitian yang digunakan adalah pendekatan cross sectional.Penarikan sampel dilakukan dengan teknik proportional random sampling dan simple random sampling dengan jumlah sampel sebanyak 142 orang. Analisis yang digunakan adalah chisquare dan uji regresi. Hasil penelitianmenunjukkan bahwa ada pengaruh signifikan antara attraction to public participation, commitment to public values, compassion, self sacrifice terhadap kepuasan kerja perawat RSUD Haji Makassar ( $p$ value $(0.001)<0.05)$ dan compassion menunjukkan pengaruh yang paling besar terhadap kepuasan kerja perawat dengan koefisien 0,519, kemudian diikuti oleh self sacrifice dengan koefisien 0.744 , commitment to public values dengan koefisien 0,482 attraction to public participationdengan koefisien 0,454
\end{abstract}

Kata Kunci: Motivasi, pelayanan publik,kepuasan kerja

\begin{abstract}
There is an intrinsic motivation that affects job satisfaction of employees in the public sector ie Public Service Motivation (PSM) where employees are more concerned with providing public services than personal interests.This study aims to analyze the influence of the dimensions of Public Service Motivation (PSM) to the satisfaction of nurses work in RSUD Haji Makassar.The study was conducted at RSUD Haji Makassar. The research used cross sectional approach. Sampling was done by proportional random sampling and simple random sampling technique with 142 samples. The analysis used is chisquare and regression test. The result of research shows that there is a significant influence between the attraction to public participation, commitment to public values, compassion, self sacrifice to the nurses 'job satisfaction of RSUD Haji Makassar ( $p$ value (0.001) $<0.05$ and the compassion dimension shows the greatest influence to the nurses' coefficient 0,519, then followed by self sacrifice with coefficient 0.744 , commitment to public values with coefficient 0,482 attraction to public participation with coefficient 0,454
\end{abstract}

Keywords: Public service motivation, job satisfaction 


\section{PENDAHULUAN}

Pengelolaan sumber daya manusia di rumah sakit diperlukan agar dapat membantu rumah sakit untuk mencapai tujuannya yaitu pelayanan yang berkualitas tidak hanya menyangkut kesembuhan dari penyakit secara fisik, tetapi juga menyangkut kepuasan terhadap sikap petugas, ketersediaan sarana dan prasarana serta lingkungan fisik untuk kenyamanan pasien (Fitrianasari et al., 2013).

Julio et al (2013), menyatakan bahwa untuk meningkatkan mutu pelayanan di Rumah Sakit maka diperlukan peningkatan mutu sumber daya manusia dan profesionalismenya. Salah satu profesionalisme yang sangat berperan adalah perawat. Menurut Baumann (2007) sumber daya manusia keperawatan merupakan faktor penting dalam melakukan pelayanan di rumah sakit, karena hampir setiap negara, hingga $80 \%$ pelayanan kesehatan diberikan oleh perawat. Maka penting untuk memperhatikan kinerja dari perawat dengan memperhatikan faktor-faktor yang memengaruhi kinerja perawat, Salah satu faktor yang berhubungan dengan kurang baiknya kinerja perawat adalah faktor kepuasan perawat dalam bekerja.

Penelitian oleh Yanidrawati (2012), memperlihatkan hanya $7,04 \%$ perawat yang puas dalam bekerja. Penelitian di Jakarta oleh Noras \& Sartika (2012), juga menyimpulkan bahwa tingkat kepuasan kerja perawat termasuk rendah yaitu $22,5 \%$. Selain itu beberapa penelitian membuktikan bahwa tetap terjadi ketidakpuasan perawat Rumah Sakit pasca implementasi JKN. Hasil penelitian oleh Nafia'ah di RS Islam Sultan Agung Semarang, menyatakan bahwa $56,5 \%$ perawat kurang puas bekerja di Rumah Sakit pasca implementasi JKN.

Banyak hal yang memengaruhi kepuasan kerja diantaranya adalah motivasi (Robbins, 2002). Maharjan (2012), menyatakan bahwa kinerja merupakan suatu hasil yang dicapai karena termotivasi dengan pekerjaan sehingga merasa puas dengan pekerjaan yang mereka lakukan.
Serupa dengan yang diungkapkan Cong \& Van (2013), bahwa motivasi berpotensi sebagai salah satu sarana terpenting dalam membentuk kepuasan kerja dan memengaruhi kinerja pegawai.

Selain itu, terdapat motivasi intrinsik yang memengaruhi kepuasan kerja pegawai di sektor publik yakni Public Service Motivation (PSM)dimana para pegawai yang lebih mementingkan memberikan pelayanan publik dibandingkan harapan atas imbalan ekonomis. Seorang pegawai yang memiliki tingkat Public Service Motivation(PSM) yang tinggi akan cenderung puas atas pekerjaannya dan berkinerja baik (Wright \& Pandey, 2008).

Ketika pegawai merasa bahwa pekerjaan mereka memberinya kesempatan untuk melayani publik akan memberi efek positif terhadap kepuasan kerja. Andersen \& Kjeldsen (2013), menambahkan individu dengan tingkat Public Service Motivation (PSM) tinggi menjadi lebih baik dalam bertindak pada motivasinya dalam pelayanan publik, jika lingkungan kerja menawarkan kesempatan untuk melayani masyarakat dan jika pegawai merasa bahwa mereka dapat usaha secara langsung pada masyarakat.

RSUD Haji Makassar merupakan salah satu rumah sakit rujukan kelas B milik pemerintah Provinsi Sulawesi Selatan Pada tahun 2015, diberitakan pada salah satu koran Tribun Timur Makassar tentang aksi mogok yang dilakukan perawat pada bulan Mei 2015. Aksi ini diungkapkan oleh perawat disebabkan kurangnya transparansi kepala rumah sakit serta tidak meratanya pembagian jasa pelayanan. Berdasarkan hasil survei kepuasan kepuasan kerja pada 35 perawat pelaksana.juga menunjukkan bahwa masih rendahnya kepuasan kerja perawat yaitu sebesar 54,3\%. Pencapaian tersebut menunjukkan adanya gap antara data rumah sakit dengan target kepuasan provider menurut BPJS yaitu $80 \%$.

Penelitian-penelitian sebelumnya menunjukkan bahwa public service motivation berpengaruh kuat terhadap 
kepuasan kerja karyawan. Penelitian yang dilakukan oleh Homberg \& McCarty (2015), memperlihatkan adanya pengaruh Public Service Motivation (PSM) terhadap kepuasan kerja yang dilakukan di sektor publik administrasi di Inggris. Penelitian serupa dilakukan di China oleh Zhu et al (2014) dan Liu et al (2014) yang menyatakan hubungan dan pengaruh Public Service Motivation (PSM) terhadap kepuasan kerja pegawainya.

Kim \& Vandenabeele (2010) menunjukkan public service motivation terbentuk dari empat dimensi yaitu Attraction to Public Participation, commitment to the public values, compassion dan self sacrifice. Keempat dimensi ini dapat memengaruhi dalam meningkatkan dan menurunkan kepuasan kerja pegawai publik secara parsial maupun simultan.

Berdasarkan latar belakang, uraian teori, penelitian-penelitian terdahulu serta kajian masalah yang telah dijelaskan sebelumnya, maka dapat dikatakan bahwa ada pengaruh antara public servuce mtivation terhadap kepuasan kerja perawat. Tujuan penelitian ini adalah untuk menganalisis menganalisis pengaruh Public Service Motivation (PSM)terhadap kepuasan kerja perawat di RSUD Haji Makassar.

\section{BAHAN DAN METODE}

\section{Lokasi dan Rancangan penelitian}

Penelitian ini telah dilaksanakan di RSUD RSUD Haji Makassar.Jenis penelitian yang digunakan adalah penelitian kuantitatif dengan menggunakan rancangan observasional analitik dengan pendekatan cross-sectional study.

\section{Populasi dan sampel}

Populasi penelitian ini adalah perawat pelaksana RSUD Haji Makassar yang berstatus Pegawai Negeri Sipil (PNS) yaitu sebanyak 193 orang. Sampel sebanyak 142 orang setelah ditambah perkiraan sampel drop out sebesar $10 \%$ yang diperoleh dengan menggunakan metode simple random sampling yang kemudian sampel diambil secara proportional sampling pada masingmasing unit kerja.

\section{Metode pengumpulan data}

Pengumpulan data kuantitatif dengan melakukan kuesioner. Instrumen kuesioner ini merupakan kuesioner terstruktur yang terdiri atas enam bagian yaitu bagian pertama terdiri atas pertanyaan demografi, 7 pertanyaan yang mengukur aspek dimensi Attraction to Public Participation, 13 pertanyaan yang mengukur aspek dimensi commitment to public values, 6 pertanyaan yang mengukur aspek dimensi compassion dan 7 pertanyaan yang mengukur aspek dimensi self sacrifice. Dan 16 pertanyaan untuk mengukur aspek kepuasan kerja. Jawaban responden dari seluruh variabel kemudian diberi skor antara 1-4 dengan pilihan jawaban dari "sangat tidak setuju" hingga "sangat setuju" dengan menggunakan skala likert.

\section{Analisis data}

Data yang telah terkumpul selanjutnya dianalisis secara kuantitatif dengan mengunakan statistik deskriptif atau inferensial sehingga dapat disimpulkan hipotesis yang dirumuskan terbukti atau tidak.Teknik analisis data yang digunakan adalah analisis univariat, yang berfungsi memberikan gambaran karakteristik populasi dan penyajian hasil deskriptif melalui frekuensi dan distribusi dari variabel bebas dan variabel terikat. Analisis bivariat, dilakukan untuk mencari ada tidaknya hubungan variabel bebas dengan variabel terikat dengan menggunakan uji chi-square. Analisis multivariat, dilakukan untuk melihat pengaruh dan arah variabel bebas terhadap variabel terikat dengan menggunakan analisis regresi linear.

\section{HASIL}

\section{Karakteristik responden}

Tabel 1 memperlihatkan karakteristik perawat yang menjadi sampel penelitian ini. Sebagian besar responden berumur antara 25-34 tahun (47,9\%).yang merupakan kelompok usia produktif. Pada umumnya kebanyakan responden berjenis kelamin perempuan $(81,7 \%)$ yang dominan 


\begin{tabular}{|c|c|c|}
\hline \multicolumn{3}{|c|}{$\begin{array}{l}\text { berstatus telah menikah }(74,6 \%) \text {. } \\
\text { Mayoritas responden berlatar belakang } \\
\text { pendidikan D3 keperawatan }(49.3 \%) \text { dan } \\
\text { dengan masa kerja lebih dari } 3 \text { tahun } \\
(91,5 \%) \text {. } \\
\text { Tabel 1. Distribusi Karakteristik Responden }\end{array}$} \\
\hline Karakteristik & Jumlah (n) & $\%$ \\
\hline \multicolumn{3}{|l|}{ Umur } \\
\hline$<25$ tahun & 5 & 3,5 \\
\hline 25-34 tahun & 68 & 47,9 \\
\hline 35-44 tahun & 59 & 41,5 \\
\hline$>45$ tahun & 10 & 7,0 \\
\hline \multicolumn{3}{|l|}{ Jenis Kelamin } \\
\hline Laki-laki & 26 & 18,3 \\
\hline Perempuan & 116 & 81,7 \\
\hline \multicolumn{3}{|l|}{ Status Perkawinan } \\
\hline Menikah & 106 & 74,6 \\
\hline Belum Menikah & 35 & 24,6 \\
\hline Pernah Menikah & 1 & 0,7 \\
\hline \multicolumn{3}{|l|}{ Tingkat Pendidikan } \\
\hline SPK & 0 & 0,0 \\
\hline Diploma 3 (D3) & 70 & 49,3 \\
\hline Strata 1 ( S1) & 24 & 16,9 \\
\hline Ners & 48 & 33,8 \\
\hline \multicolumn{3}{|l|}{ Masa Kerja } \\
\hline$\leq 3$ Tahun & 12 & 8,5 \\
\hline$>3$ tahun & 130 & 91,5 \\
\hline Total & 142 & 100,0 \\
\hline
\end{tabular}

Sumber: Data Primer

\section{Analisis Univariat Variabel Penelitian}

Tabel 2 menunjukkan bahwa dari 142 responden, jumlah responden dengan tingkat public service motivation tinggi $(80,3 \%)$ lebih banyak dibandingkan responden dengan public service motivationrendah (19,7\%). Tingkat attraction to public participation yang tinggi $(68,3 \%)$ lebih dominan dibandingkan responden dengan tingkatattraction to public participationyang rendah $(31,7 \%)$. Tingkat commitment to public valuesyang tinggi $(66.2 \%)$ lebih dominan dibandingkan responden dengan tingkatcommitment to public valuesyang rendah $(33,8 \%)$. Tingkat compassion yang tinggi $(73,9 \%)$ lebih dominan dibandingkan responden dengan tingkatcompassion yang rendah $(26,1 \%)$. Tingkat self sacrifice yang tinggi $(65,5 \%)$ lebih dominan dibandingkan responden dengan tingkatself sacrifice yang rendah $(34,5 \%)$. Sedangkan untuk aspek kepuasan kerja perawat, maka responden dengan tingkat kepuasan kerjatinggi lebih banyak $(69,7 \%)$ dibandingkan responden dengan tingkat kepuasan kerja rendah $(30,3 \%)$. 
Tabel 2. Distribusi Frekuensi Public Service Motivation (PSM), Attraction to Public Participation (APP), Commitment to Public Values (CPV), Compassion (COM), Self Sacrifice (SS) dan Kepuasan Kerja di RSUD Haji Makassar Tahun 2017

\begin{tabular}{|c|c|c|c|}
\hline No. & Variabel Penelitian & Jumlah (n) & Persen (\%) \\
\hline \multirow[t]{3}{*}{1} & Public Service Motivation & & \\
\hline & Tinggi & 28 & 19,7 \\
\hline & Rendah & 114 & 80,3 \\
\hline \multirow[t]{3}{*}{2} & Attraction to Public Participation & & \\
\hline & Tinggi & 45 & 31,7 \\
\hline & Rendah & 97 & 68,3 \\
\hline \multirow[t]{3}{*}{3} & Commitment to Public Values & & \\
\hline & Tinggi & 48 & 33,8 \\
\hline & Rendah & 94 & 66,2 \\
\hline \multirow[t]{3}{*}{4} & Compassion & & \\
\hline & Tinggi & 37 & 26,1 \\
\hline & Rendah & 105 & 73,9 \\
\hline \multirow[t]{3}{*}{5} & Self Sacrifice & & \\
\hline & Tinggi & 49 & 34,5 \\
\hline & Rendah & 93 & 65,5 \\
\hline \multirow[t]{3}{*}{6} & Kepuasan Kerja & & \\
\hline & Tinggi & 43 & 30,3 \\
\hline & Rendah & 99 & 69,7 \\
\hline Tota & & 142 & 100 \\
\hline
\end{tabular}

Sumber: Data Primer, 2017.

\section{Analisis Multivariat}

Pada variabel PSM, tabel 4 menunjukkan nilai nilai $\mathrm{t}$ hitung $=9,232>\mathrm{t}$ tabel $=1,960$ dan nilai $\mathrm{p}=0,001<\alpha=0,05$. Artinya bahwa adanya pengaruh public service motivation terhadap kepuasan kerja. Maka dapat disimpulkan bahwa hipotesis null ditolak dan hipotesis alternatif (H5) diterima yaitu Public Service Motivation (PSM) berpengaruhterhadap kepuasan kerja perawat di RSUD Haji Makassar.

Pada dimensi APP, tabel 4 menunjukkan nilai nilai t hitung $=6,026>\mathrm{t}$ tabel $=1,960$ dan nilai $p=0,001<\alpha=0,05$. Artinya bahwa adanya pengaruh dimensi attraction to public participationterhadap kepuasan kerja. Maka dapat disimpulkan bahwa hipotesis null ditolak dan hipotesis alternatif (H1) diterima yaitu dimensi Public Service Motivation (PSM) yaitu attraction to public participation berpengaruhterhadap kepuasan kerja perawat di RSUD Haji Makassar.

Pada dimensi CPV, tabel 4 menunjukkan nilai nilai $\mathrm{t}$ hitung $=6,506>\mathrm{t}$ tabel $=1,960$ dan nilai $p=0,001<\alpha=0,05$. Artinya bahwa adanya pengaruh dimensi

commitment to public values terhadap kepuasan kerja. Maka dapat disimpulkan bahwa hipotesis null ditolak dan hipotesis alternatif (H2) diterima yaitu dimensi Public Service Motivation (PSM) yaitu commitment to public values berpengaruhterhadap kepuasan kerja perawat di RSUD Haji Makassar.

Pada dimensi COM, tabel 4 menunjukkan nilai nilai $\mathrm{t}$ hitung $=7,178>\mathrm{t}$ tabel $=1,960$ dan nilai $p=0,001<\alpha=0,05$. Artinya bahwa adanya pengaruh dimensi compassionterhadap kepuasan kerja. Maka dapat disimpulkan bahwa hipotesis null ditolak dan hipotesis alternatif (H3) diterima yaitu dimensi Public Service Motivation (PSM) yaitu compassion berpengaruhterhadap kepuasan kerja perawat di RSUD Haji Makassar. Pada dimensi SS, tabel 4 menunjukkan nilai nilai $\mathrm{t}$ hitung $=6,825>\mathrm{t}$ tabel $=1,960$ dan nilai $\mathrm{p}=0,001<\alpha=0,05$. Artinya bahwa adanya pengaruh dimensi self sacrifice 
terhadap kepuasan kerja. Maka dapat disimpulkan bahwa hipotesis null ditolak dan hipotesis alternatif (H4) diterima yaitu dimensi Public Service Motivation (PSM) yaitu dimensi self sacrifice berpengaruhterhadap kepuasan kerja perawat di RSUD Haji Makassar.

Tabel 4. Analisis Mulltivariat antara Public Service Motivation (PSM) Attraction to Public Participation (APP), Commitment to Public Values (CPV), Compassion (COM), Self Sacrifice (SS) terhadapKepuasan KerjaPerawat di RSUD Haji Makassar Tahun 2017

\begin{tabular}{lllll}
\hline Variabel & R Square & Stand. Coeff & T & Sig \\
\hline PSM* JS & 0,378 & 0,615 & 9,232 & 0,001 \\
APP* JS & 0,206 & 0,454 & 6,026 & 0,001 \\
CPV* JS & 0,232 & 0,482 & 6,505 & 0,001 \\
COM* JS & 0,269 & 0,519 & 7,178 & 0,001 \\
SS* JS & 0,250 & 0,500 & 6,825 & 0,001 \\
\hline
\end{tabular}

Sumber: Data Primer, 2017.

\section{PEMBAHASAN}

Hasil penelitian menunjukkan bahwa variabel PSM maupun dimensinya yaitu attraction to public participation, commitment to public values, compassion dan self sacrifice berpengaruh terhadap kepuasan kerja perawat. Hal ini artinya semakin tinggi tingkat PSM serta empat dimensinya akan meningkatkan pula kepuasan kerja yang dirasakan perawat.

Penelitian Andersen \& Kjeldsen (2013), yang menyatakan bahwa PSM dan kepuasan kerja memiliki hubungan yang positif signifikan. Hasil penelitian ini sejalan dengan berbagai penelitian lainnya oleh Steijn (2008); Taylor (2008); dan Wu (2012) yang menemukan bahwa adanya pengaruh yang positif antara PSM terhadap kepuasan kerja pegawai publik.

Premis yang mendasari adanya keterkaitan adalah bahwa organisasi publik memberikan kesempatan kepada karyawan untuk melayani masyarakat, yang memotivasi karyawan dengan tingkat yang lebih tinggi dari PSM, dan dengan demikian menyebabkan kepuasan kerja yang lebih tinggi (Andersen \& Kjeldsen, 2013 ; Bright, 2008). Salah satu perspektif yang dapat menghubungkan keterkaitan antara PSM dan kepuasan kerja adalah teori tentang P-O fit. Dalam teori P-O fit menunjukan kompatibilitas antara lingkungan individu dan lingkungan kerja dapat mempengaruhi kinerja individu. Sederhananya diungkapkan bahwa adanya interaksi antara manusia dan lingkungan berpengaruh pada sikap dan perilaku kerja (Bright2008; Kim2012; Steijn2008).

Keterkaitan dimensi APP terhadap kepuasan kerja perawat, sejalan dengan penelitian oleh Nattee et al (2012), yang menunjukkan bahwa persepsi tentang tujuan/sasaran organisasi memiliki pengaruh yang positif terhadap motivasi 
pelayanan publik terhadap empat dimensi PSM salah satunya adalah attraction to public policy making.

Sejalan dengan yang dijelaskan oleh Perry \& Wise (1990) bahwa konsep public service motivationyaitu motif rasional (rational motives) merujuk setiap tindakan yang diambil oleh seseorang untuk mencapai tujuan terbesar dari kepuasannya. Hal ini dapat dicapai ketika orang tersebut terlibat dalam proses perumusan kebijakan dan partisipasi dalam pembuatan kebijakan yang menghasilkan motif dalam pekerjaan mereka dan membangun citra diri mereka. Motif rasional (rational motives) dapat memotivasi seseorang dalam daya tariknya terhadap pembuatan kebijakan publik, komitmen terhadap program publik dan kepuasan dalam memberikan pelayanan publik (Nattee et al., 2012).

Keterkaitan dimensi CPV terhadap kepuasan kerja perawat, sejalan dengan penelitian dari Li (2010), yang menyatakan bahwa dimensi dari PSM yaitu dimensi public interest berhubungan signifikan dengan kepuasan kerja.Dimensi commitment to public values berkaitandengan motif normatif (normative motives). Motif normatif didasarkan pada nilai-nilai sosial dan norma dari apa yang pantasdan tepat karena aksi sosial menggabungkan unsur kehendak individu secara sukarela dan kolektivisme yang diwakili oleh internalisasi norma-norma sosial (Knoke \& Wright-Isak 1982).Motif ini melibatkan dedikasi terhadap suatu sebab dan keinginan untuk melayani kepentingan umum, namun hal itu dirasakan.Sehingga mereka termasuk keinginan untuk mengejar kepentingan umum. Selanjutnya kepentingan umum mengekspresikan rasa kewajiban dan kesetiaan kepada pemerintah (Perry \& Wise 1990).

Keterkaitan dimensi COM terhadap kepuasan kerja perawat, sejalan dengan penelitian dari $\mathrm{Wu}$ (2010), yang menyatakan bahwa adanya hubungan positif dari tingkat compassion terhadap level kepuasan kerja. Dimensi compassion terkait dengan motif afektif (affective motive). Motif afektif (affective motive) mengacu pada tindakan yang didasarkan pada respons emosional manusia terhadap berbagai konteks sosial.Dalam hal ini, emosi digunakan sebagai dasar motivasi. Selain itu compassion dikaitkan dengan konteks social.Motif afektif ditandai dengan keinginan dan kemauan untuk membantu orang lain, dan termasuk altruisme, empati dan keinginan prososial lainnya (Brewer et al., 2000).

Keterkaitan dimensi SS terhadap kepuasan kerja perawat, sejalan dengan penelitian dari Zhu et al(2014), yang menyatakan bahwa Dimensi PSM yaitu self sacrifice berpengaruh positif terhadap 
kepuasan kerja.Norma dan emosi yang kuat untuk mengabdi pada sektor publik diperlukan kesesuaian nilai-nilai organisasi dengan nilai-nilai individu. individu dan organisasi saling tertarik manakala terdapat kesesuaian (compatibility) antara satu dengan yang lain. Supplementary fit dicapai ketika organisasi menarik orangorang yang tujuan dan nilainya mencerminkan nilai mereka sendiri (Bright, 2007). Pegawai negeri yang puas dengan pekerjaan mereka akan merasa bahwa pekerjaan mereka memungkinkan untuk pemenuhan nilai-nilai yang penting bagi mereka.Sehingga pengorbanan diri adalah salah satu nilai inti pada sektor publik. Dengan demikian, responden dengan nilai pengorbanan lebih tinggi akan lebih puas dengan pekerjaan mereka karena nilainya sama dengan semangat sektor publik (Liu et al., 2008).

Hasil penelitian ini menunjukkan dimensi yang paling besar pengaruhnya terhadap kepuasan kerja perawat yaitu dimensi compassion. Hasil penelitian ini sejalan dengan studi yang dilakukan Liu et al(2008), yang menunjukkan bahwa motif normatif (commitment to publik interest) memiliki pengaruh yang relatif lemah terhadap kepuasan kerja daripada motif rasional (Attraction to public policy making) dan motif afektif (compassion).Karyawan akan perlu memiliki keinginan yang kuat untuk melayani masyarakat sebelum mereka dapat, misalnya, rela mengorbankan mendapatkan imbalan intrinsik atau menjadi peka secara emosional dengan konteks sosialnya. Kepuasan kerja yang dimodelkan sebagai fungsi dari pengalaman kerja, khususnya kapasitas pekerjaan untuk memenuhi keinginan karyawan, kemungkinan akan lebih didorong oleh keinginan untuk membantu masyarakat (motif normatif) bagi yang memiliki PSM tinggi, dan kurang untuk memenuhi kebutuhan pribadi (motif rasional).

\section{KESIMPULAN DAN SARAN}

Kami menyimpulkan bahwa tingkat kepuasan kerja perawat dipengaruhioleh attraction to public participation, commitment to public values, compassion, self sacrifice di RSUD Haji. Dimensi compassion menunjukkan pengaruh yang paling besar terhadap kepuasan kerja perawat, kemudian diikuti oleh self sacrifice, commitment to public valuesdan attraction to public participation. Maka disarankan sebaiknya dalam rekrutmen dan seleksi dalam mendapatkan karyawan (perawat) baru hendaknya perlu memastikan perawat yang benar-benar mempunyai kompetensi tinggi, disiplin, orientasi pada tujuan yang ingin dicapai organisasi publik. Selain itu perlunya penerapan kepemimpinan transformational 
sehingga partisipasi yang besar dari

perawat diperlukan oleh organisasi baik dalam hal penyusunan serta penerapan kebijakan ataupun program rumah sakit.

\section{DAFTAR PUSTAKA}

Andersen, L. B. \& Kjeldsen, A. M. (2013). Public service motivation, user orientation, and job satisfaction: A question of employment sector. International Public Management Journal, 16:252-274.

Baumann, A. (2007). Positive Practivce Environment : $\quad$ Quality Workplace $=$ Quality Patient Care.International Council of Nurses.

Brewer, G.A., Selden, S.C., \& Facer, R.L. (2000). Individual conceptions of public service motivation. Public Administration Review, 60(3):25463.

Bright, L. (2007). Does personorganization fit mediate the relationship between public service motivation and the job performance of public employees?. Review of Public Personnel Administration, 27 (2):361-79.

Bright, L. (2008). Does Public Service Motivation Really Make a Difference on the Job Satisfaction and Turnover Intentions of Public Employees?. The American Review of Public Administration, 38 (2):149-166.

Cong, N.N. \& Van, D.N. (2013). Effect of Motviaton and Job Satisfaction on Employees Performance at Petrovietnam Nghe an Construction Joints Stock Corporation (PVNC). International Journal of Humanities and Social Science, 4(6).

Fitrianasari, D., Nimran, U.,\& Utami, H. (2013). Pengaruh Kompensasi dan Kepuasan Kerja terhadap
Organizational Citizenship

Behavior (OCB) dan Kinerja Karyawan (Studi pada Perawat Rumah Sakit Umum). Jurnal Profit, 7(1):12-24.

Homberg, F., Mccarthy, D.,\& Tabvuma, V. (2015). A meta-analysis of the relationship between public service motivation and job satisfaction. Public Administration Review, 75:711-722.

Julio, Dewi, S.C.,\& Kartika, E.W. (2013). Analisa pengaruh Leader Member Exchange, Perceived Organizational SUpport terhadap Kepuasan Kerja Karyawan dengan Motivasi Kerja sebagai Variabel Mediator di Hotel Tarakan Plaza. Jurnal Universitas Kristen Petra.

Kim, S. \&Vandenabeele, W. (2010). A strategy for building public service motivation research internationally. Public Administration Review, 70:701-709.

Kim, S. (2012). Does Person-Organization Fit Matter in the Public-Sector? Testing the Mediating Effect of Person- Organization Fit in the Relationship between Public Service Motivation and Work Attitudes. Public Administration Review, 72(6):830-840.

Knoke, D.\& Wright-Isak, C. (1982). Individual Motives and Organizational Incentive Systems. Research in the Sociology of Organization, 1:209-254.

Li, X. (2010). Public Service Motivation Research, in View of China's MPA Graduate. Social Science Press :177-197.

Liu, B., Tang, N.,\& Zhu, X. (2008). Public service motivation and job satisfaction in China: An investigation of generalisability and instrumentality. International Journal of Manpower, 29:684-699.

Liu, B., Zhang, X., \& Lv, X. (2014). Compassion as the Affective Dimension of Public Service Motivation in a Chinese Context. 
Social Behavior and Personality: An International Journal, 42(2):245-251.

Maharjan, S. (2012). Association between work motivation and job satisfaction of college teachers. Journal of Administrative and Management Review, 24(2):45-55.

Nattee, K., Trichan, C., \& Lerkiatbundit, S. (2012). Factors Affecting public service motivation: empirical study of municipal employees in the three southern border provinces of thailand. International Journal of Business and Social Science, 3(18):78-86.

Noras, J. U. \& Sartika, R. A. D. (2012). Perbandingan Tingkat Kepuasan Kerja Perawat dan Kepuasan Pasien. Kesmas: National Public Health Journal, 6:234-240.

Perry, J. L. \& Wise, L. R. (1990). The motivational bases of public service. Public administration review:367-373.

Robbins, S.P. (2002). Perilaku OrganisasiEdisi Delapan.Jakarta: Penerbit Perhallindo.

Steijn, B. (2008). 'Person-Environment Fit and Public Service Motivation. International Public Management Journal, 11(1):13-27.

Taylor, J. (2008). Organizational Influences, Public Service Motivation and Work Outcomes: An Australian Study. International Journal of Public Management, 11(1): 67-88.

Wright, B. E.\& Pandey, S. (2008). Public Service Motivation and the Assumption of Person-Organization Fit: Testing the Mediating Effect of Value Congruence. Administration and Society, 40(5):502-521.

$\mathrm{Wu}$, S.H. (2010). Relationships among civil servants' job satisfaction, organizational commitment and public service motivation. Human Resource Development of China, 9.

Yanidrawati, K. (2012). Hubungan Kepuasan Kerja Dengan Kinerja
Perawat Di Ruang Rawat Inap

Rumah Sakit Umum Daerah Kabupaten Bekasi. Students eJournal, 1(32).

Zhu, C., Wu, C.,\& Yan, M. (2014).

Evidence of Public Service Motivation and Job Satisfaction of Public Sector Employees in China. Business and Public Administration Studies, 8:34-47. 